[38] Concentration of blood-pigment in the cerebrospinal fluid as a result of the action of histamine (Der Farbstoffübertritt vom Blut in den Liquor unter dem Einfluss von Histamin).-HeLmut Sprockhoff. Deut. Zeits. f. Nervenheilk., 1935, 137, 277.

THE question is discussed whether the products of disintegration arising in the body, which act on the bloodvessels, may have an influence upon the permeability of the bloodvessels in the brain. Experiments performed on dogs showed that the pharmacological representative of such substances of disintegration, viz., histamine, enables fuchsin $S$ to penetrate into the cerebrospinal fluid. Other experiments were performed in order to ascertain the regions in which this permeability is increased By histamine.

M.

\title{
SENSORIMOTOR NEUROLOGY
}

[39] Ependymal tumour of the spinal cord and progressive spinal muscular atrophy (Ependimomatosi midollare e atrofia musculare progressiva spinale).-G. Pintus. Riv. di pat. nerv. e ment., 1935, 45, 591.

A CASE is described of progressive muscular atrophy of the spinal type which, besides some atypical distribution of the muscular atrophy, did not present when examined electrically during its whole course of nearly two years any signs of the reaction of degeneration, but only simple hypoexcitability with at most some slow contractions or slight increase so that the polar reactions were equal.

Autopsy showed the following findings : A proliferation of the ependymal cells so that the central canal was entirely obliterated throughout the length of the medulla. The character of the cells indicated that the condition represented a midway position between ependymal tumour-formation and simple proliferation similar to what occurs in a gliosis.

Lacunæ were also found in the region of the grey commissure. These might be due to the enlargement of the perivascular spaces and alteration of the surrounding nervous tissue, but also possibly to the circulation of the liquor pressed out of its usual channels by the obliteration of the central canal.

Finally there was a great reduction in the number of anterior horn cells in the whole length of the spinal cord, especially in the region of the cervical and lumbar enlargements. There was a slight lymphocytic reaction round a certain number of the vessels of medium calibre, especially those lying between the white and grey matter.

This condition should be distinguished from chronic poliomyelitis of the adult. It showed no signs of inflammatory origin, and while it might be due to toxic causes, it was impossible to exclude an embryonic origin. 
No remedy used, whether drugs or physical methods, succeeded in arresting the fatal progressive course of the malady.

R. G. G.

[40] X-ray changes in the vertebral laminæ in cases of spinal cord tumour (Über Wirbelbogenveränderungen bei Rückenmarkstumoren im Rœntgenbild).-H. Stefan. Zeits. f. d. g. Neurol. u, Psychiat., 1934, 151, 683.

THE results previously reported by Elsberg and Dyke (Bulletin of the Neurological Institute of Nerw York, 1934, 3, 3) were confirmed. In many cases of spinal cord tumour characteristic alterations were observed on X-ray examination of the vertebral column.

[41] Tumours in the spinal canal in childhood.-W. B. HAmBy. Jour. Nerv. Ment. Dis., 1935, 81, 24.

A STUDY of 100 cases of spinal tumour in childhood described in the literature, with the addition of one case. This review shows that the characteristic tumours of infancy and early childhood are lipomas and dermoids, while meningiomas and chloromas occur only late in the period of childhood. Sarcomas, gliomas, lipomas and neurinomas may occur at any time throughout the period.

R. G. G.

[42] Echinococcus affecting the vertebral column and spinal cord (Echinococcus der Wirbelsäule und des Ruckenmarks).-N. H. Popow and B. J. Umerow. Deut. Zeits. f. Nervenheilk., 1935, 137, 186.

Echinococcus of the spinal cord is a rare disease. As a rule the abdominal and thoracic cavities are the primary site with a secondary penetration into the spinal column. Primary involvement by echinococcus of the vertebræ themselves is very rare. A subdural or intramedullary localization of the parasite has been observed in very few cases up to the present time. An example is described in this communication. An unusual phenomenon observed was the disappearance followed by reappearance of the ankle-jerks, the latter occurring possibly as a result of a biological process in the parasitic cyst, such as the splitting off of a daughter cyst. Characteristic changes produced by the echinococcus appears to be demonstrable on X-ray examination, viz. destruction of the body of a vertebra with formation of cavities showing a rounded and regular form. 
[43] Intramedullary tumours of the brainstem.-C. C. HARE and A. Wolf. Arch. of Neurol. and Psychiat., 1934, 32, 1230.

THE clinical signs and autopsy findings in seven cases of glioma of the brainstem are reported. In three of the seven cases the neoplasm was an astrocytoma fibrillare, in three a glioblastoma multiforme and in one a polar spongioblastoma. The histological structure was similar to that found in the same types of tumours situated elsewhere in the brain. The extent of the neoplasms as seen at autopsy was usually much greater than one would have suspected from a study of the clinical signs and the course of the disease.

Considerable difficulty may be encountered in establishing the clinical diagnosis in a case of tumour of the brainstem. A history taken carefully and completely with regard to the manner of onset of illness and the progression of symptoms is of great diagnostic aid. If a diagnosis of tumour of the posterior fossa is established, and there are signs of a nuclear involvement of the cranial nerves, one should suspect that the lesion is completely or partially intramedullary. The intramedullary gliomas are somewhat more frequent in children than in adults. An exploratory operation of the posterior cranial fossa should be performed if there is doubt whether the tumour is inside or outside the brainstem. If the localization is obviously intramedullary, cranial operative procedure is contraindicated.

R. M. S.

[44] A new syndrome in the diagnosis of tumour of the corpus callosum (Ein neues Syndrom zur Diagnostik von Balkentumoren).-J. Michelsen. Deut. Zeits. $f$. Nervenheilk., 1935, 137, 152.

ThE following symptoms were observed in seven cases of tumour of the corpus callosum : (1) Profound mental alteration without predominance of any particular psychiatric type; (2) increase in the body-temperature without demonstrable infection; (3) xanthochromia and an increase of cells in the cerebrospinal fluid.

M.

[45] Arachnoiditis of the optic chiasma (L'aracnoidite del chiasma nei nervi ottici).-G. Lo Cascio. Riv. di pat. nerv. e ment., 1935, 44, 638.

A CASE is described in full. The clinical course was about two years. The initial symptoms were headache and restriction of vision first in the left eye and then spreading to the right. Progress was intermittent with exacerbations of headache and diminution of vision amounting to almost complete amblyopia. These symptoms were of short duration and were accompanied by polyuria and somnolence and once by an epileptic fit. 
So far as treatment is concerned most authorities advise surgical intervention. Radiological treatment is not yet far enough advanced to be confidently recommended while drug treatment may be useful in syphilitic and other specific infections.

R. G. G.

[46] The relation between non-suppurative disseminated encephalomyelitis and disseminated sclerosis (Zur Frage der Beziehungen zwischen des disseminierten nichteitrigen Encephalomyelitis und der multiplen Sklerose).-G. Peters. Zeits.f.d.g. Neurol.u. Psychiat., 1935, 153, 356.

A REPORT on two cases of non-suppurative disseminated encephalomyelitis which could be distinguished from disseminated sclerosis on clinical as well as on histological examination. Other authors, however, described cases in which no such distinction can be made. For this reason it is considered that no fundamental differentiation exists between the two conditions either from a clinical or from a pathological standpoint.

M.

[47] Acute aseptic meningitis.-H. R. VIETs and J. W. WATts. Jour. Nerv. Ment. Dis., 1935, 80, 253.

Further examinations of cases now amounting to 14 of acute aseptic meningitis. The cerebrospinal fluid in this condition is characterized by a lymphocytic pleocytosis though occasionally polymorphs may be seen. Clotting may also occur in the fluid. Sugar and chlorides are always normal in contradistinction to the findings in tubercular meningitis. The condition should be considered as a clinical entity as no definite relationship, in the authors' view, exists between it and other morbid states.

R. G. G.

[48] Encephalomyelitis disseminata following ascending neuritis.-Ross $\mathbf{H}$. Thompson. Jour. Nerv. Ment. Dis., 1935, 81, 373.

THE possibility of infection in the central nervous system by spread along the lymphatics surrounding the peripheral nerves is illustrated by a case of typical ascending neuritis following a purulent infection of the left index finger and hand and definitely involving the outside column of the left side. The process continued for 59 days, gradually spreading inwards and causing paræsthesiæ of lower segments and upwards so as to result not only in pyramidal involvement but also diplopia and nystagmus. From this it would 
appear that there must be direct connexion between the lymph spaces of the perineural sheaths and the spinal subarachnoid space.

R. G. G.

[49] Contribution to the symptomatology of disseminated sclerosis (Beitrag zur Symptomatologie der multiplen Sklerose).-G. Peters and H. Lewenstein. Deut. Zeits. f. Nervenheilk., 1935, 137, 119.

A GIRL of 25 began to suffer from a mental disturbance which continued up to her death at the age of 28. The physical signs of disseminated sclerosis developed only ten days before the fatal termination. The mental symptoms were those of an amentia with an intermittent exacerbating course, of the type supposed to be characteristic in mental disturbances resulting from disseminated sclerosis.

M.

[50] A rare form of periodic paraplegia ( $\mathrm{Su}$ di una rara forma di paraplegia periodica).-A. Capelli. Riv. di pat. nerv. e ment., 1935, 44, 382.

THE case described showed an organic process causing complete transverse destruction of the spinal cord with ascending and descending degeneration of tracts. Clinically the case was marked by frequent and rapid periodicity during the course of the disease. The periodicity may have been due to extraneous events such as menstruation, abortion and therapeutic intervention, which probably acted by increase or decrease in the filling of local vessels. It is impossible to be sure of the reason for the periodicity, but in any case this would appear to be a rare form of spinal paraplegia.

R. G. G.

[51] Colloidal thorium dioxide : its use in intracranial diagnosis and its fate on direct injection into the brain and the ventricles.-L. Alexander. T. S. Jung and R. S. Lyman. Arch. of Neurol. and Psychiat., 1934, 32, 1143.

Colloidal thorium dioxide allows visualization of the cerebral arteries, but the injection of this substance into dogs shows that if it enters the brain proper it acts as a foreign substance. The possibility of harm from intracarotid injections of colloidal thorium dioxide seems to lie in the more remote effects of thorium in the body.

R. M. S. 
[52] Polycythæmia vera and its neuropsychiatric features.-N. W. WinkeLmax and M. A. Burns. Jour. Nerv. Ment. Dis., 1933, 78, 597.

Two cases of polycythæmia vera, showing mental and nervous manifestations, are reported. The subjective complaints are usually headache, giddiness, and scotomata. The mental phenomena did not fit in with any psychiatric picture, but confusion and deterioration have been the predominant signs.

Microscopic examination of the nervous system of one of the cases showed such dilatation and engorgement of the blood vessels that stasis had resulted with anoxæmic changes in the ganglion-cells. The blood vessels themselves were extremely tortuous and frequently swelling of the lining cells had occurred to such a degree that denudation was noted.

The histological picture presented in this case will readily explain the neuropsychiatric complications.

R. G. G.

[53] The clinical aspect of Cushing's disease (Ein Beitrag zur Klinik der Morbus Cushing).-W. Schoen. Deut. Zeits. f. Nervenheilk., 1935, 137, 177.

A TYPICAL case of Cushing's syndrome is described with symptoms of adiposity, genital dystrophy, hypertonia and glycosuria together with osteoporosis. An adenoma in the anterior lobe of the pituitary body was the basis of the disorder. Bilateral temporal hemianopia with optic atrophy was also present. The basal metabolic rate was increased $(+23)$. Mental disturbances are noted in some cases, e.g. that of a girl aged 25, formerly quite normal, who showed the intelligence of a child of seven; she was also irritable and uncontrolled.

The author considers it doubtful if the alteration in the pituitary body was primary in nature or the result of pathological processes elsewhere in the body, as, in addition to the pituitary, other endocrine organs often show a disturbance of function.

M.

[54] The migrainous patient: a constitutional study.-G. A. Touraine and G. Draper. Jour. Nerv. Ment.'Dis., 1935, 80, 1.

ThIs is an attempt to establish a constitutional type in migraine. The authors suggest that it is possible to recognize a skull conformation with acromegaloid trends, an outstanding intelligence and a retarded emotional development. The headaches tend to be similar in nature and occasion of onset in practically all cases, and they tend to begin when the individual is required to face situations on his own in the absence of customary home 
protection and support. There seems to be a family tendency chiefly on the maternal side and the possibility of imitative derivation should not be lost sight of. In the opinion of the authors the physical symptoms and the disturbance of physiological processes are secondary to and precipitated by an emotional discharge. This probably accounts for the fact that a large number of remedies may be successful tor a time, but cure is alleged only to result if and when the patient ever grows up on his emotional side.

R. G. G.

\section{PROGNOSIS AND TREATMENT}

[55] Diathermy in the treatment of general paralysis.-HARRY J. WorTHIng. Psychiatric Quarterly, 1933, 7, 245.

IT was thought that possibly the method of producing fever by the use of a mechanical method might bring about satisfactory results and have less disadvantages than malarial therapy. The application of treatment by diathermy is here described. Though only a comparatively small number of cases (i.e. six) were experimented with, the findings mostly agree with those of others who have used diathermy over a longer period. A similar and controllable fever simulating that of malaria could be produced, but the patients expressed extreme discomfort when the temperature rose above $102^{\circ} \mathrm{F}$. and begged that the treatment be discontinued. The white blood corpuscles and red corpuscles increased during each individual treatment, the red-cell rise being as much as one million, and the white cells from 1,000 to 4,000 . With this increase the cell count showed a reduction in percentage of the lymphocytes and rise in the percentage of polymorphonuclears. There was loss in weight after each treatment, varying from $\frac{1}{2}$ to $2 \mathrm{lb}$. Clinically there was mental improvement in three of the patients. One recovered, left the hospital and maintained himself. In three the colloidal gold curve showed a pronounced reduction. In three there was no change. Blood and spinal fluid Wassermann tests were not modified. This writer feels we must not be too hasty in dispensing with malaria, though there undoubtedly will be a place for diathermy with the more co-operative patients.

C. S. R.

[56] Life expectancy in general paresis.-Irving M. Derby. Psychiat. Quarterly, 1935, 9, 458.

MALARIA and other therapy that has increased the average duration of life in paretics has been utilized over so recent a time that it is too early to evaluate completely a correct expectancy of life. At the Brooklyn State Hospital in a series of $\mathbf{8 7 0}$ admissions, 225 patients are still alive-several 